Results Overall, the survey has a high internal consistency (Cronbach's $\alpha=0.742$ ). Some sections require a further factor analysis, such as current health outlook, $(\mathrm{KMO}<0.823$, $\mathrm{p}<0.001)$ and reasons for risk-taking $(\mathrm{KMO}<0.604$, $\mathrm{p}=0.003)$. Some sections indicate the requirement for a larger sample size for further validation, such as safety consideration for other players $(\mathrm{KMO}<0.48, \mathrm{p}<0.001)$. The participants' qualitative comments on the viability of customising OSH concepts to sports context was also considered to refine the survey. Most players indicated a better understanding of risks relating to themselves than risks relating to opposition players.

Conclusions Such a survey enables the measuring of athletes' safety and risk awareness level, which could possibly point the way forward for its application in a wider range of sport settings internationally for improving athletes' long-term health and wellbeing.

\section{KNOWLEDGE OF THE IMPORTANCE OF PROPER TACKLE CONTACT TECHNIQUES DOES NOT TRANSLATE TO PROPER TACKLE CONTACT TECHNIQUE FOR INJURY PREVENTION AND PERFORMANCE}

${ }^{1}$ Steve den Hollander, ${ }^{1}$ Mike Lambert, 1,2,3 Ben Jones, 1,2 Sharief Hendricks. ${ }^{1}$ Division of Exercise Science and Sports Medicine, Department of Human Biology, Faculty of Health Sciences, the University of Cape Town and the Sports Science Institute of South Africa, Cape Town, South Africa, Cape Town, South Africa; ${ }^{2}$ Institute for Sport, Physical Activity and Leisure, Leeds Beckett University, Leeds, UK, Leeds, UK; ${ }^{3}$ School of Science and Technology, University of New England, NSW, Australia, Armidale, Australia

\subsection{6/bjsports-2021-IOC.420}

Background In rugby union and sevens, the tackle is the most frequently occurring contact event and carries the greatest risk of causing injury. Proper tackle technique has been shown to reduce the risk of injury during the tackle and increase likelihood of success. As such, national rugby injury prevention programmes aim to provide coaches, trainers and players with knowledge of proper tackle technique. This knowledge is intended to modify players behaviours towards safety in the tackle, and ultimately improve their tackle technique in training and matches.

Objectives To determine the association between knowledge of the importance of proper tackle contact techniques and actual proper tackle contact technique for injury prevention and performance.

Design Cross-sectional study design.

Participants Fifty-three $(n=53)$ academy rugby players participated in this study, and a total of 211 tackles were analysed.

Assessment of Risk Factors Knowledge and attitudes of proper contact technique for injury prevention and performance for both the ball-carrier and tackler were determined using a questionnaire. In training, players performed four ball-carries into contact and four tackles using a validated tackle drill. Thereafter, technical proficiency for the ball-carrier and tackler were scored using a standardised technical criteria.

Main Outcome Measurements Knowledge and attitude score for proper tackle contact technique for injury prevention and performance, technical proficiency score for the ball-carrier and tackler.

Results No association was found between player knowledge of the importance of techniques and actual tackle contact technique in training for both injury prevention (tackler $r=$ $0.02, \mathrm{p}=0.90$; ball-carrier $\mathrm{r}=-0.26, \mathrm{p}=0.06$ ) and performance (tackler $\mathrm{r}=0.02, \mathrm{p}=0.86$; ball-carrier $\mathrm{r}=-0.13$, $\mathrm{p}=0.38)$.

Conclusions This study reveals the gap between players' declarative knowledge of safe and effective techniques and their procedural knowledge of how to execute proper techniques. This gap supports the argument that injury prevention programmes should not be limited to educational strategies only, and should include practical coaching components.

\section{HITS IN RUGBY LEAGUE: BETTER NEVER THAN LATE}

${ }^{1,2}$ Declan Patton, ${ }^{1,3}$ Colin Huber. ${ }^{1}$ Center for Injury Research and Prevention, Children's Hospital of Philadelphia, Philadelphia, USA; ${ }^{2}$ Sport Injury Prevention Research Centre, University of Calgary, Calgary, Canada; ${ }^{3}$ Department of Bioengineering, University of Pennsylvania, Philadelphia, USA

\subsection{6/bjsports-2021-IOC.421}

Background A late hit in rugby league is when a player is tackled after passing or kicking the ball and is deemed player misconduct by the National Rugby League (NRL). During the 2019 season, the NRL cracked down on late hits as the struck player is typically in a vulnerable position and/or unaware and unable to brace for the impact.

Objective To (1) identify body regions of contact for striking and struck players involved in late hits, (2) compare the anthropometrics of striking and struck players involved in late hits and (3) compare the rate of late hit penalties before and after the crackdown.

Design Descriptive observational study.

Setting NRL 2019 regular season.

Main Outcome Measurements Body regions of contact for striking and struck players as determined by two independent video reviewers and subsequent consensus. Height and weight of striking and struck players as per the NRL player profile. Late hit penalty rate calculated on a per game basis.

Results A total of 29 late hit penalties were identified, most of which involved the shoulder of the striking player $(73 \%)$ impacting the back $(52 \%)$ or side $(28 \%)$ of the struck player. The majority of the striking players were forwards (93\%) with a mean height and weight of $1.89 \pm 0.05 \mathrm{~m}$ and 106.3 $\pm 5.8 \mathrm{~kg}$, respectively, which were significantly greater $(\mathrm{p}<0.001)$ than struck players (mean height, $1.82 \pm 0.07 \mathrm{~m}$; mean weight, $91.4 \pm 8.4 \mathrm{~kg}$ ) who were predominantly backs (79\%). Before the crackdown, there were 0.12 late hit penalties per game, which increased to 0.18 per game after the crackdown.

Conclusions A typical late hit involved the shoulder of a larger player colliding with the back or side of a smaller player. The rate of late hit penalties increased after a crackdown by the NRL suggesting that referees were more vigilant in penalising late hits. 